\title{
PRÁTICAS EDUCATIVAS INCLUSIVAS NA EDUCAÇÃO INFANTIL: SUPERANDO A MARCAÇÃO SOCIAL DE GÊNNERO E RAÇA ENTRE AS CRIANÇAS PEQUENAS
}

\begin{tabular}{c}
\hline INCLUSIVE EDUCATIONAL PRACTICES IN EARLY CHILDHOOD EDUCATION: \\
OVERCOMING THE SOCIAL MARKING OF GENDER \\
AND RACE AMONG YOUNG CHILDREN \\
\hline PRÁCTICAS EDUCATIVAS INCLUSIVAS EN LA EDUCACIÓN INFANTIL: \\
SUPERANDO LA MARCACIÓN SOCIAL DE GÉNERO \\
Y RAZA ENTRE LOS NIÑOS PEQUEÑOS
\end{tabular}

Elizabete Cristina Costa-Renders ${ }^{1}$ Rosana Donizeti Martinho Gazotto ${ }^{2}$

Cleia Souza Santos ${ }^{3}$

RESUMO: Este artigo relata um processo de reflexão sobre a própria prática educativa que aconteceu no âmbito dos estudos da disciplina Educação Inclusiva, num programa de mestrado profissional em educação, oferecido por uma universidade pública municipal. Aborda os relatos de 02 professoras que atuam na Educação Infantil a partir da seguinte pergunta: como as práticas educativas cotidianas podem contribuir para a construção da escola inclusiva? Opta pelo estudo sistemático da marcação social da diferença entre as crianças pequenas (gênero e raça) a partir da interface entre as políticas de educação inclusiva e as práticas na educação infantil. Os estudos fundamentaram-se no referencial teórico do paradigma da inclusão, trabalhando temas como diversidade, inclusão e múltiplas linguagens na Educação Infantil. Esta ação reflexiva resultou em duas proposições: 1. Há meios para rompermos com a marcação de raça e gênero nos cotidianos das instituições de Educação Infantil; 2. Há um potencial inclusivo nas brincadeiras e no brincar com os brinquedos não estruturados, quando este sustenta-se nos princípios éticos e estéticos multiculturais.

PALAVRAS-ChAVE: Educação inclusiva. Educação infantil. Práticas educativas. Gênero. Etnia. Diferenças.

ABSTRACT: This article shares a reflection about an educational practice that took place within the framework of the studies of Inclusive Education in a Professional Master Program in Education offered by a municipal public university. It opts for the systematic study of the social marking of the difference among young children (gender and race) based on the interface between inclusive education policies and practices in early childhood education. The study is based on the theoretical framework of the inclusion paradigm and themes like diversity, inclusion and multiple languages in the Early Childhood Education. This reflexive action resulted in two propositions: 1. There are ways to break with the marking of race and gender in the daily life of schools; 2 . There is an inclusive potential in games and playing with unstructured toys, so far that it is based on multicultural ethical and aesthetic principles.

KEYWORDS: Inclusive education. Early childhood education. Educational practices. Gender. Ethnicity. Differences.

\footnotetext{
${ }^{1}$ Submetido em: 06/04/2018 - Aceito em: 21/04/2018 - Publicado em: 31/12/2018
}

\begin{tabular}{l|c|c|c|c|c|c} 
(C) Rev. Educ. Perspec. & Viçosa, $M G$ & v.9 & n.2 & p.414-433 & maio/ago. 2018 & eISSN 2178-8359 \\
\hline
\end{tabular}


RESUMEN: Este artículo relata un proceso de reflexión sobre la propia práctica educativa que tuvo lugar en el marco de los estudios de la disciplina Educación Inclusiva, en un programa de maestría profesional en educación, ofrecida por una universidad pública municipal. Aborda los informes de 02 profesoras que actúan en la Educación Infantil a partir de la siguiente pregunta: ¿como las prácticas educativas cotidianas pueden contribuir a la construcción de la escuela inclusiva? Opta por el estudio sistemático del marcado social de la diferencia entre los niños pequeños (género y raza) a partir de la interfaz entre las políticas de educación inclusiva y las prácticas en la educación infantil. Este recorrido se basó en el apoyo teórico del paradigma de la inclusión, trabajando temas como diversidad, inclusión y múltiples lenguajes en la Educación Infantil. Esta acción reflexiva resultó en dos proposiciones: 1. Hay medios para romper con la marcación de raza y género en los cotidianos de las escuelas; 2. Hay un potencial inclusivo en los juegos y jugar con los juguetes no estructurados, cuando éste se sustenta en los principios éticos y estéticos multiculturales.

PAlabRas Clave: Educación inclusiva. Educación infantil. Prácticas educativas. Género. Etnicidad. Diferencias.

\section{INTRODUÇÃO}

Este artigo resulta da aproximação das experiências de três professoras aos estudos sobre a inclusão educacional no Brasil. Considerando a inserção de duas destas professoras em instituições de Educação Infantil, bem como os estudos no contexto da disciplina Educação Inclusiva (PPGE/USCS, 2017), trabalhamos a interface entre os princípios da educação inclusiva (respeito às diferenças, educação como direito humano, igualdade de acesso e permanência na instituição educacional) e a atual política de Educação Infantil (criança como sujeito de direito, integração do cuidar/educar, centralidade do brincar, múltiplas linguagens).

As experiências relatadas ocorreram em instituições de Educação Infantil na região da grande São Paulo, instituições nas quais trabalham duas das professoras autoras deste artigo. Ambas cursaram a disciplina Educação Inclusiva, no segundo semestre de 2017, como parte da sua formação no Programa de Pós-Graduação em Educação da Universidade Municipal de São Caetano do Sul (USCS). Juntamente com a professora responsável pela disciplina (autora principal deste artigo), foram consideradas as documentações pedagógicas elaboradas pelas referidas professoras no ano de 2016, bem como as memórias dos cotidianos docentes, intencionalmente retomadas num processo de reflexão sobre a própria prática na perspectiva do paradigma da inclusão.

A pergunta geradora deste estudo foi: como as práticas educativas cotidianas de professoras e professores podem contribuir para a construção da Educação Infantil inclusiva? Neste texto, responderemos tal questão a partir de três eixos. Primeiro, apresentaremos as políticas inclusivas em interface com as políticas para a Educação Infantil no Brasil. Em seguida, discorreremos sobre o enfrentamento da marcação de gênero e do racismo entre as crianças pequenas. Por fim, destacaremos o potencial inclusivo do brincar na Educação Infantil. 


\section{AS POLÍTICAS INCLUSIVAS EM INTERFACE COM AS POLÍTICAS PARA A EDUCAÇÃO INFANTIL NO BRASIL}

Na primeira década deste século, tem crescido a relevância do pensar as necessidades educativas das crianças que frequentam as unidades de Educação Infantil. Especialmente, há que compreendermos este campo como um espaço em que o cuidar e o educar se tornam indissociáveis, dentro da perspectiva das múltiplas experiências acessíveis a todas as crianças, sem distinção. Neste sentido, a Educação Infantil deve oportunizar o desenvolvimento integral, reconhecendo a criança como sujeito histórico, cultural e plural.

O direito da criança à Educação Infantil é uma garantia constitucional desde 1988, a qual encontra respaldo na Lei de Diretrizes e Bases da Educação Nacional, Lei N. 9394/1996, segundo a qual, no Art. 11, inciso V, os municípios devem se responsabilizar pela Educação Infantil e o Ensino Fundamental, priorizando o segundo (BRASIL, 1996). Evidentemente, uma questão que, imediatamente, se coloca é: como a priorização do Ensino Fundamental pelos municípios coloca sob tensão a perspectiva inclusiva da Educação Infantil?

A universalização do acesso ao sistema de ensino é uma das diretrizes principais da educação inclusiva no Brasil, entendendo-se que, desde a Educação Infantil até à Educação Superior, há que se garantir a "igualdade de acesso e permanência" (BRASIL, 1988) para todos. Voltando-nos para a Lei N. 9394/1996, o Art. 29, dispõe que a Educação Infantil é "a primeira etapa da educação básica, tem como finalidade o desenvolvimento integral da criança de até 5 (cinco) anos, em seus aspectos físico, psicológico, intelectual e social, complementando a ação da família e da comunidade". Ainda, segundo o Art. 30, esta etapa educacional deve ser oferecida, em "creches, ou entidades equivalentes, para crianças de até três anos de idade e em pré-escolas, para as crianças de 4 (quatro) a 5 (cinco) anos de idade" (BRASIL, 1996). Portanto, como parte integrante da Educação Básica, a Educação Infantil também deve garantir o acesso para todas as crianças brasileiras. Todavia, a priorização do Ensino Fundamental, muitas vezes, coloca nuvens sobre o direito das crianças pequenas à educação, persistindo numa visão segmentada e assistencialista que é herança das históricas políticas segregacionistas. Historicamente, a educação das crianças menores de seis anos, foi marcada pelo assistencialismo e exclusão, sem a garantia deste direito à todas as crianças (KUHLMANN, 2000).

A história da Educação Infantil no Brasil foi marcada por concepções assistencialistas que entendiam as creches como espaços para cuidar das crianças em situação de pobreza, oferecendo, apenas, os cuidados com o alimentar, o dormir e a higiene pessoal. Tradicionalmente, as creches cuidavam das crianças enquanto os pais permaneciam trabalhando, sendo que o direito à vaga era da família, especialmente, da mãe trabalhadora. 
Neste cenário, a criança permanecia como sujeito passivo e sem direitos.

A legislação atual, no entanto, dispõe que todas as crianças têm direito ao acesso às instituições educacionais, inclusive às creches. Na atual política educacional, a Educação Infantil ganha legitimidade social, superando a diferenciação deste direito entre as crianças com base na renda familiar. Neste sentido,

\begin{abstract}
[...] o atendimento em creches e pré-escolas como um direito social das crianças se concretiza na Constituição de 1988, com o reconhecimento da Educação Infantil como dever do Estado com a Educação, processo que teve ampla participação dos movimentos comunitários, dos movimentos de mulheres, dos movimentos de redemocratização do país, além, evidentemente, das lutas dos próprios profissionais da educação. A partir desse novo ordenamento legal, creches e pré-escolas passaram a construir nova identidade na busca de superação de posições antagônicas e fragmentadas, sejam elas assistencialistas ou pautadas em uma perspectiva preparatória a etapas posteriores de escolarização (BRASIL, 2010, p. $81)$.
\end{abstract}

A integração da Educação Infantil aos sistemas educacionais não, necessariamente, tem proporcionado a superação da concepção assistencialista e constituído a indissociabilidade entre o cuidar/educar neste campo educacional. Tendo em perspectiva o desenvolvimento integral de todas as crianças, há que nos atentarmos para a tensão entre segmentação e integração que ainda persiste, seja no campo da Educação Infantil ou no campo da Educação Inclusiva.

A discussão no sentido da superação da visão assistencialista e segmentada também se coloca de forma relevante nos processos e implementação da educação inclusiva. O paradigma da inclusão nos desafia a superar a visão assistencialista e caritativa que produziu a posição de dependência das crianças em situação de pobreza.

Noutra perspectiva há que considerarmos os dados do racismo no Brasil. Segundo relatório recente da Organização das Nações Unidas, a pobreza no Brasil tem cor, pois os negros respondem por 70,8\% dos 16,2 milhões de brasileiros vivendo em extrema pobreza e por $80 \%$ dos analfabetos do país. Os salários médios dos negros no Brasil chegam a ser 2,4 vezes menores do que os recebidos por cidadãos brancos (ONU, 2016). Entendemos que, se esta é a realidade das famílias das crianças negras no Brasil, o racismo é um problema a ser enfrentado também na Educação Infantil.

Se reconhecemos a criança como um sujeito histórico e produtora de conhecimento, como sujeito de direito interagindo com o contexto social, há que insistirmos no entendimento da Educação Infantil como espaço do cuidar/educar, de forma integral, para todas as crianças. É preciso, portanto, prever condições para o "reconhecimento, a valorização, o respeito e a interação das crianças com as histórias e as culturas africanas, afro-brasileiras, bem como o

\begin{tabular}{l|l|l|l|l|l|l} 
(C) Rev. Educ. Perspec. & Viçosa, $M G$ & v.9 & n.2 & p.414-433 & maio/ago. 2018 & eISSN 2178-8359 \\
\hline
\end{tabular}


combate ao racismo e à discriminação" (BRASIL, 2010, p. 21) também nas instituições educacionais.

A ação do cuidar exige perceber o outro, num olhar sensível que reconheça as necessidades de todas as crianças no seu processo de desenvolvimento, integrando o cuidar ao educar. A integração destas ações, atualmente, se coloca como princípio norteador do trabalho com a primeira infância, pois é "dever do Estado garantir a oferta de Educação Infantil pública, gratuita e de qualidade, sem requisito de seleção" (BRASIL, 2010, p. 12), respeitando o direito de ser, sendo diferente, de todas as crianças. Aos professores e professoras cabe, portanto, superar o entendimento da diferença como problema, transformando-a num valor pedagógico.

A partir do entendimento da Educação Infantil como um dever do Estado, colocam-se avanços importantes rumo às instituições educacionais inclusivas. A Educação Infantil ganha novas características como espaço coletivo institucional. Um espaço, portanto, não doméstico, mas, sim, público e democrático, que deve ser acessível para todas as crianças brasileiras nos termos do paradigma da inclusão. Neste contexto da transição paradigmática do assistencialismo para a educação como direito, colocam-se desafios como: a constituição de políticas públicas intersetoriais, a formação em serviço dos seus profissionais e a ampliação das vagas nas creches. Entendemos que estes desafios estão postos tanto para a Educação Infantil quanto para os diferentes âmbitos que demandam abordagens pedagógicas inclusivas.

Neste cenário, também ganha destaque a pergunta pela qualidade da Educação Infantil oferecida às crianças pequenas no Brasil. Todavia, segundo Moss, o "conceito de qualidade não é neutro nem isento de valores. É resultado de um modo específico de se ver o mundo e está permeado de valores e pressupostos. Trabalhar com o conceito de qualidade é uma opção, não uma necessidade" (MOSS, 2002, p. 17). Assim, ao pensarmos a qualidade da Educação Infantil, o fazemos na perspectiva do paradigma da inclusão, o qual reconhece a educação como direito humano de todas as crianças e preconiza o respeito às diferenças sem segmentá-las e hierarquizá-las.

Entendemos que as práticas educativas no âmbito da Educação Infantil, como espaço coletivo institucionalmente educacional, visam compreender e desenvolver ações integradas, respeitando a diversidade e as singularidades de todas as crianças atendidas por este segmento. Quanto às práticas pedagógicas na Educação Infantil, as diretrizes nacionais dispõem que a 
conhecimentos e aprendizagens de diferentes linguagens, assim como o direito à proteção, à saúde, à liberdade, à confiança, ao respeito, à dignidade, à brincadeira, à convivência e à interação com outras crianças (BRASIL, 2010, p. 18).

Feitas as primeiras aproximações entre as políticas de Educação Infantil e Educação Inclusiva, é perceptível a necessidade do enfrentamento da marcação social da diferença para a exclusão nas instituições educacionais. Neste cenário, é o paradigma da inclusão que sinaliza o que seria uma escola de qualidade para todos (MANTOAN, 2013). Mas as experiências que, aqui, serão narradas, apontam, especialmente, a segmentação de meninos e meninas e a hegemonia da estética branca nos cotidianos escolares. Tais questões, portanto, devem "ser objeto de constante reflexão e intervenção no cotidiano da educação infantil" (BRASIL, 2010, p. 10), tendo em perspectiva a construção da educação para todos.

Consideramos que a centralidade da criança com produtora de cultura (FARIA; FINCO, 2011) também ganha relevância neste processo, pois o ato de brincar, em suas múltiplas linguagens, corporifica o processo de aprendizagem das crianças pequenas como sujeitos construtores. Para as crianças, os percursos de descobertas surgem a partir das múltiplas formas em que o mundo a elas se revela, favorecendo a articulação dos múltiplos saberes e a expressão em múltiplas linguagens. Tal perspectiva nos remete ao multiculturalismo que demanda a superação da imposição da monocultura nos espaços educacionais. As monoculturas são modos de produção de ausência (SANTOS, 2008) que, historicamente, tem legitimado a seleção, classificação e exclusão educacional de algumas crianças dentre elas as crianças negras e as meninas. Entendemos que a educação infantil inclusiva exige abertura às múltiplas linguagens e meios de expressão e criação. Neste cenário, coloca-se o potencial inclusivo do brincar, das brincadeiras e dos brinquedos não estruturados.

A Educação Infantil deve respeitar as diferenças e as múltiplas aprendizagens, aguçando a curiosidade epistemológica das crianças, pois

[...] brincar junto com outras requer da criança ajustes de comportamentos, de ideias do que pode ser a brincadeira. Algumas brincadeiras evidenciam uma compreensão mútua das crianças a respeito de alguns comportamentos que se destacam da interação entre elas e passam a sinalizar 'algo'. Esse 'algo' pode ser uma mensagem, como, por exemplo, um riso alto para que o outro impulsione o balanço com mais força (OLIVEIRA, 2000, p. 56).

O brincar junto oportuniza o aprender a respeitar as diferenças, o reconhecimento mútuo e o cuidar um do outro. Desde a primeira infância, deve-se reconhecer o direito da criança como um sujeito ativo no aprender cotidiano, atendendo as suas peculiaridades e oportunizando trocas e partilhas no grupo. À medida que a criança cresce, ela vai construindo seus saberes a partir da socialização com as outras crianças e com o mundo em que está inserida. 
As instituições de Educação Infantil devem democratizar o acesso e qualificar as condições de permanência para todas as crianças, sem diferenciação socioeconômica, étnico-racial, de gênero, cultural e de acessibilidade. A Lei de Diretrizes e Bases da Educação Nacional de 1996, como já vimos, dispõe que a Educação Infantil, como primeira etapa da Educação Básica, deve promover o desenvolvimento integral de todas as crianças, observando os aspectos físico, psicológico, intelectual e social. A perspectiva inclusiva, portanto, deve perpassar todo este processo, enfrentando as barreiras que, ainda, estão postas às crianças.

\section{O ENFRENTAMENTO DA MARCAÇÃO DE RAÇA E GÊNERO ENTRE AS CRIANÇAS PEQUENAS}

Os espaços educacionais, como construção social, configuram-se em múltiplas possibilidades de aprendizagens e interações, onde é possível perceber que as crianças são protagonistas. Neste sentido, há que perguntarmos também pela recriação do modelo educativo.

\footnotetext{
A recriação do modelo educativo vigente refere-se primeiramente ao que ensinamos aos nossos alunos e como ensinamos para que eles cresçam e se desenvolvam, como seres éticos, dignos, pessoas que têm de reverter uma situação que não conseguimos ainda resolver inteiramente: mudar o mundo e torná-lo mais humano (MANTOAN, 2013, p. 101).
}

Nesta perspectiva, entendemos que a reflexão sobre a própria prática educativa (FREIRE, 1997) e sobre as formas de marcação das diferenças de gênero e raça na Educação Infantil é de extrema relevância no sentido da construção das escolas inclusivas no Brasil. Deste modo, a seguir, propomos a reflexão sobre estas questões a partir de alguns relatos dos cotidianos de instituições de Educação Infantil.

\section{A questão da etnia na instituição educacional}

No Brasil, a Lei N. 11645 de 2008 torna obrigatório o estudo sobre a História e Cultura AfroBrasileira e Indígena nas instituições públicas (BRASIL, 2008). Neste cenário, a luta dos negros pela valorização da sua cultura, considerando sua contribuição na formação da sociedade brasileira, busca resgatar a contribuição do povo negro nas áreas social, econômica e política da história do Brasil. É neste contexto que ganha relevância a referida lei. Há que discutirmos e difundirmos a narrativa da história dos negros pelos próprios negros, considerando que esta foi, durante séculos, negligenciada frente à narrativa europeia.

As Diretrizes Curriculares Nacionais para Educação Étnico Racial (BRASIL, 2004) dispõem que as instituições de ensino devem incluir os conteúdos e questões sobre a temática étnicoracial na matriz curricular. Estes dispositivos legais são fruto de movimentos sociais que buscam a superação do racismo e a necessidade de combatê-lo frente ao mito da igualdade

\begin{tabular}{l|l|l|l|l|l|l} 
(C) Rev. Educ. Perspec. & Viçosa, $M G$ & v.9 & n.2 & p.414-433 & maio/ago. 2018 & eISSN 2178-8359 \\
\hline
\end{tabular}


racial no Brasil. A seguir, destacamos uma cantiga de roda que circulou (e talvez ainda circule) em algumas instituições de Educação Infantil, a qual testemunha o predomínio da mentalidade colonialista e escravocrata na sociedade brasileira:

\author{
Plantei uma cenoura no meu quintal \\ Nasceu uma negrinha de avental \\ Dança negrinha \\ Não sei dançar \\ Pega no chicote \\ Que ela dança já (AUTOR DESCONHECIDO).
}

Esta cantiga aponta a necessidade de superação do racismo e vem ao encontro das políticas públicas destinadas à valorização da diversidade étnico-racial no contexto das ações cotidianas nos diferentes segmentos escolares. Se, segundo os dados estatísticos do Censo do Instituto Brasileiro de Geografia e Estatística (IBGE, 2010), mais da metade da população brasileira, cerca de 54\%, são pretos ou pardos, as instituições de Educação Infantil, como espaços educativos, devem evidenciar as abordagens étnico-raciais para todas as crianças e, em especial, para as crianças negras. Especialmente, apresentando-lhes representações positivas dos povos africanos.

As crianças negras são sujeitos históricos e demandam a valorização da cultura em matrizes africanas. $\mathrm{O}$ que nos leva a questionar como está o acesso à cultura africana e a consideração da diversidade étnico-racial na Educação Infantil. No entanto, há, ainda, que apontarmos a ausência das representações sociais de determinadas crianças no contexto da instituição de Educação Infantil, bem como a violência simbólica (e, por vezes, física) que afeta as crianças negras no Brasil.

$\mathrm{Na}$ ausência de representações sociais fora da dicotomia hierárquica branco/negro, colocamse também as angústias no ato de pronunciar o "quem sou eu". A seguir, destacamos as palavras de um estudante universitário que, na vida adulta, retoma suas angústias da infância:

\footnotetext{
Eu nunca soube o que eu era. Nunca consegui me definir de maneira segura para terceiros, muito menos para mim mesmo. Em censos e pesquisa, assinalava a opção "pardo". Em parte, por ter sido dito que essa era a minha cor. Em parte, por não ter coragem de assinalar a palavra "negro". Nunca soube o que eu era. O que eu sempre soube, todavia, era o que eu não era. Eu não era branco. Isso ficou muito claro pra mim desde minha infância, quando adentrei em uma escola particular onde era o único aluno "moreninho". Toda piada ou observação sobre negro vinha as minhas custas. Todo apelido pejorativo sobre negro era meu. Lembro que, sempre ao sair da aula, era chamado de "Dani Kibe" pelo tom de pele da minha cor (NOVA, 2017).
}

Noutra perspectiva, as crianças negras tendem a incorporar padrões estéticos da beleza branca também nos momentos lúdicos vivenciados nas instituições educacionais, sendo que isto se passa, de forma significativa, pela estética do seu cabelo. O cabelo crespo, desconsiderado no

\begin{tabular}{l|c|c|c|c|c|c} 
() Rev. Educ. Perspec. & Viçosa, $M G$ & v.9 & n.2 & p.414-433 & maio/ago. 2018 & eISSN 2178-8359 \\
\hline
\end{tabular}


contexto da identidade racial, aponta o quanto as crianças são submetidas a hábitos de manipulação do cabelo para que estes moldem-se aos padrões dos cabelos lisos e compridos. Estando fora deste padrão, a criança negra sofre com as preconceituosas expressões "cabelo de bombril", "nega do cabelo duro", "amarra ou corta este cabelo ruim", etc. Notamos também que, raramente, o cabelo de uma criança negra é acariciado ou elogiado na instituição de Educação Infantil.

Importa considerarmos que "há codinomes que expressam que o tipo de cabelo do negro é visto como símbolo de inferioridade, sempre associado à artificialidade. Esses apelidos recebidos na escola marcam a história de vida dos negros" (GOMES, 2007, p. 45). Entretanto, defendemos que "o cabelo e a cor da pele podem sair do lugar da inferioridade e ocupar o lugar da beleza negra, assumindo uma significação política e pedagógica” (GOMES, 2007, p. 49) de forma positiva. Ou seja, podemos ressignificar as diferenças no campo da diversidade cultural.

Este é mais um dos motivos que faz da instituição educacional um local para debates e reflexões no sentido da superação dos preconceitos em relação à estética negra. Relatamos, aqui, a experiência vivida em uma instituição de Educação Infantil pública municipal.

Tudo começou quando um grupo de alunas estava passeando pelo recreio e foi abordado por um grupo de meninos de outra turma. Estes meninos passaram a verbalizar palavras como "cabelo de esponja" e "cabelo duro", bem como puseramse a gargalhar. Este fato se deu com uma aluna negra estrangeira, que recentemente havia chegado do Haiti. Ela assumia sua negritude, usando cabelo Black e, por isso, foi alvo de um vocabulário preconceituoso de crianças que já incorporaram o discurso depreciativo que desqualifica a cultura negra, a começar pelo cabelo (Relato da professora 2).

A manifestação dos referidos alunos mostra que conviver numa sociedade inclusiva demanda que as crianças conheçam com maior profundidade a história cultural deste país. Especialmente, exige que destaquemos a contribuição da cultura negra na história das sociedades. Os mecanismos de transmissão do preconceito racial revelam a necessidade de suscitar discussões que envolvam compreender as raízes africanas deste país, ao lado das suas raízes europeias e indígenas, pois todas elas contribuíram para a diversidade cultural da nação brasileira.

O respeito à diversidade cultural requer a pergunta pela constituição de identidade da criança negra como apontou Nova (2017). Há que compreendermos que a construção desta identidade também se dá no contexto escolar, especialmente na Educação Infantil. O resgate histórico proposto pela Lei N. 11645 de 2008 considera as possíveis relações entre educação, cultura e sociedade na formação da identidade negra, oferecendo uma atenção diferenciada às questões da corporeidade e da estética. Neste sentido, os processos educativos demandam 
discussões a respeito das representações e concepções, por exemplo, do cabelo crespo, as quais devem ser construídas a partir das memórias do povo negro.

Às instituições educacionais cabe realizar debates e pensar estratégias pedagógicas que permitam problematizar os padrões estéticos impostos às crianças. Não podemos mais encobrir as raízes dos negros vindos da diáspora, a cor da sua pele e a textura do seu cabelo para atender às expectativas da hegemônica estética branca. Importa, portanto, considerarmos como a mentalidade colonialista e escravocrata, ainda, tem afetado as crianças pequenas neste país, sejam elas negras ou brancas.

O paradigma educacional inclusivo demanda a construção de um novo olhar, que compreenda a história de vida de meninos e meninas negras. A instituição educacional precisa romper com as concepções marcadas por estereótipos preconceituosos, especialmente, em relação às crianças negras. No Brasil, a marcação social da diferença racial passa pela perspectiva do fenótipo, pelo preconceito de marca (PIBID, 2010), ou seja, por elementos da aparência como o tipo de cabelo e o tom da pele negra, atestando um parâmetro universal que reforça a visibilidade negativa da corporeidade negra. No sentido de rompermos este ciclo preconceituoso, há que constituirmos práticas culturais inclusivas nas instituições de Educação Infantil, especialmente, oferecendo às crianças pequenas os meios para a constituição de subjetividade com base na autoestima positiva. O brincar, como ato criativo, pode contribuir neste processo.

O cabelo, como veículo de ideologia, pode receber novos olhares para uma composição de estilos. Uma brincadeira que realce diferentes cortes de cabelo, tranças e penteados, pode fazer com que a criança negra venha orgulhar-se de suas raízes africanas. As crianças podem ir abandonando, assim, a pressão pelos traços da aparência da cultura europeia. Em especial, também as mães podem se libertar da pressão pelos tratamentos químicos que transformam os cabelos crespos em cabelos alisados e esticados, perdendo a beleza de sua origem. Eis um relato de experiência relativo a esta problemática.

\footnotetext{
Por vezes, as famílias são influenciadas por uma cultura predominantemente "branca" e buscam meios para as crianças não serem alvo de calúnias e representações negativas referentes ao cabelo crespo. Muitas vezes isto se mostra na forma como as mães penteiam as crianças, principalmente as meninas negras. Mantendo os cabelos crespos curtos ou amarrados, esticando os cabelos com pequenos elásticos apertados que transformam os fios de cabelo, as famílias adotam uma estética próxima à branca. Esticar o cabelo, inclusive, ferindo o couro cabeludo é uma violência com a criança (Relato da professora 2).
}

Há que nos atermos ao trabalho pedagógico que visa a superação de uma atitude de intervenção identitária. O cabelo como símbolo de uma conjuntura política, histórica e social transmite mensagens, especialmente,

\begin{tabular}{l|c|c|c|c|c|c} 
(C) Rev. Educ. Perspec. & Viçosa, $M G$ & v.9 & n.2 & p.414-433 & maio/ago. 2018 & eISSN 2178-8359 \\
\hline
\end{tabular}


[...] os cabelos rebeldes, soltos e descuidados podem expressar independência ou mesmo relutância às normas sociais, como é o caso de líderes religiosos, profetas, rastafaris. É muito comum encontrarmos entre os/as docentes a presença de relatos que associam os cabelos rastafaris e a estética dos integrantes do movimento hiphop à sujeira e à marginalidade (NARÔ, 2013, p. 49).

Estas marcas morais remetem à cultura do embranquecimento incorporado desde a infância pelos negros, os quais vão entendendo o cabelo afro como algo ruim, feio, bagunçado. Neste cenário cabe considerarmos a manipulação da identidade deteriorada nos termos de Goffman (1988) e Gomes (2007). Segundo Gomes, mudar o cabelo, por um lado, pode significar uma tentativa de escapar do lugar de inferioridade direcionado ao grupo negro (seria a manipulação da identidade deteriorada em Goffman). Mas, por outro lado, pode ser uma expressão de autonomia e uso criativo do cabelo. A subjetividade da criança negra constrói-se na afirmação da pluralidade étnico-racial, na busca da valorização da estética negra também nos cotidianos da escola. Entendemos que discutir os processos de manipulação da identidade nas instituições educacionais é relevante no sentido da superação dos estigmas raciais e também da marcação da diferença de gênero, como veremos a seguir.

\section{A questão de gênero na instituição educacional}

O direito à Educação Infantil com qualidade, na perspectiva inclusiva, demanda a discussão das questões de gênero nos cotidianos das crianças pequenas. As relações construídas pelas crianças nas instituições educacionais apresentam-se como uma das formas de sua introdução na vida social. Neste sentido, a instituição precisa estimular o respeito às diferenças sem marcá-las no sentido da segregação ou hierarquização, mas oportunizando as múltiplas experiências no cotidiano educacional.

$\mathrm{O}$ contato uns com os outros, o toque com carinho e afeto. $\mathrm{O}$ ambiente decorado de forma cuidadosa, composto por estímulos visuais, táteis e estímulos auditivos como diferentes culturas musicais. Os cuidados corporais como a higiene do corpo, a troca de fraldas, o uso do banheiro e o banho. $\mathrm{O}$ ato de pentear cabelos e escovar os dentes. Tudo isto deve contribuir para o desenvolvimento integral das crianças pequenas na Educação Infantil. A instituição educacional se coloca, portanto, como um meio de produção cultural.

Importa considerarmos a instituição de Educação Infantil não, apenas, como reprodutora das concepções de gênero, mas também como produtora destas concepções. As práticas educativas podem imprimir marcas na história de vida e na autoestima também das crianças pequenas. Entendemos, portanto, que gênero se torna uma categoria de análise indispensável na dinâmica das experiências vividas pelas crianças na Educação Infantil. Refletir sobre a questão de gênero na Educação Infantil exige que nos aproximemos do campo da sociologia da infância, retomando categorias como "tempo", "culturas infantis" e Pedagogia da

\begin{tabular}{l|c|c|c|c|c|c} 
(C) Rev. Educ. Perspec. & Viçosa, $M G$ & v.9 & n.2 & p.414-433 & maio/ago. 2018 & eISSN 2178-8359 \\
\hline
\end{tabular}


Educação Infantil. Tal aproximação nos qualifica para o desenvolvimento do pensamento crítico quanto às práticas educativas e à construção cultural do feminino e masculino desde as infâncias.

O conceito de gênero está relacionado fundamentalmente aos significados que são atribuídos a ambos os sexos em diferentes sociedades. É "a construção social que uma dada cultura estabelece ou elege em relação a homens e mulheres, meninos e meninas" (FINCO; OLIVEIRA, 2011, p. 56). Portanto, esta é uma categoria de análise diretamente relacionada aos processos educacionais, seja em âmbito formal ou não formal. Observando o espaço da instituição de Educação Infantil e acompanhando sua rotina diariamente, as experiências das professoras revelam o quanto esse espaço pode se apresentar como produtor e/ou reprodutor de atitudes e comportamentos sexistas, inclusive, os advindos das culturas familiares. Isto, muitas vezes, tem acarretado determinações e limites nas atitudes, nas práticas e no comportamento de meninos e meninas.

Podemos começar perguntando como os mecanismos de controle ou emancipação se fazem presentes na educação de meninas e meninos, inclusive, no afetamento de seus corpos. Muitas vezes, instituições como família e escola, orientam e reforçam habilidades específicas para cada sexo, transmitindo expectativas do que é considerado "mais adequado" para as meninas e para os meninos, manipulando-os com recompensas e sanções sempre que tais expectativas são ou não satisfeitas. As experiências vividas pelas professoras, participantes deste estudo e reflexão, corroboram esta perspectiva, como o que se relata a seguir.

\footnotetext{
$\mathrm{Na}$ creche, tivemos um aluno chamado L. que tinha o costume de vestir-se com roupas de meninas quando sua turma ia à brinquedoteca. Mais do que vestir-se, aliás, L. fazia muitos desenhos das figuras femininas com muitos detalhes. L. brincava com meninos e meninas, às vezes, até se metia em algum conflito físico com alguma criança. Os meninos e meninas da turma eram indiferentes à sua preferência pelos vestidos na hora da brinquedoteca. Prosseguindo o relato, ao conversar com a mãe, a mesma relatou que L. gostava muito de desenhos de princesas, e em casa, ele, algumas vezes aprontava e vestia as roupas da irmã. A mãe disse que aceitava mais tranquilamente essas situações que o pai, que já havia repreendido o menino e batido nele, por conta destes incidentes. Solicitei às crianças que elaborassem seu autorretrato para colocarem na capa do portfólio que levariam para casa no encerramento do semestre letivo. L. desenhou-se como uma princesa bailarina! (Relato da professora 1).
}

Numa situação como esta, em primeiro lugar, vem à tona o receio que a criança sofra violência em casa devido a sua atitude. No trabalho com a formação de professoras da Educação Infantil, escutamos muitas histórias parecidas quanto à reação violenta de parte da família frente à situação que coloca em questão a sua visão cultural sobre os papéis, socialmente, determinados para meninas e meninos. Nestas ocasiões, as professoras tendem a ceder para proteger a criança, como fez esta professora:

\begin{tabular}{l|c|c|c|c|c|c} 
(C) Rev. Educ. Perspec. & Viçosa, $M G$ & v.9 & n.2 & p.414-433 & maio/ago. 2018 & eISSN 2178-8359 \\
\hline
\end{tabular}


Pergunto a L.se seus pais gostarão do desenho que ele fez para a capa? L. faz uma pausa e responde: a mamãe sim, mas o papai não. E agora, L., como poderemos resolver? L. disse que gostou muito de seu desenho e que não queria fazer outro e que também não queria apanhar do seu pai e foi aí que fiz um combinado com L. (de fato não sei se foi adequado, mas precisava resolver aquela angústia de L.) e ele resolveu deixar o desenho em meu mural. Assim, ele poderia ver quando quisesse e fez outro dele vestido de uniforme e sem usar a cor rosa que segundo ele não estava bonito (Relato da professora 1).

Desde muito cedo, a instituição educacional dispõe sobre deveres, normas, regras e, entre todos esses fatores, institui os tempos e lugares para meninos e meninas separadamente, como o que se dá nos conteúdos curriculares diferenciados. Para as meninas, aulas de culinária, bordados, dotes voltados para uma "perfeita" esposa e mãe. Para os meninos, aulas de esportes, atividades que estimulassem e desenvolvessem o lado másculo, atlético, de homem forte e inteligente. Legitima-se, com isso, a visão da mulher como frágil e do homem como forte.

Se, por um lado, temos a marcação de gênero incorporada na cultura das famílias, por outro lado, professoras e professores também podem reproduzir (ou não) esta percepção sobre gênero nas práticas educativas. Por exemplo, quando um dos meninos (os mais vigiados por sua masculinidade) resolve brincar de casinha, isto pode ser visto como problema, como alvo de preocupação por parte de professoras e professores. Há também a linguagem visual e verbal dos currículos e livros didáticos que, muitas vezes, reforçam a educação sexista. Como é possível superar tais mentalidades nas instituições de Educação Infantil?

Entendemos que há meios para rompermos com a marcação de raça e gênero nos cotidianos das instituições educacionais, um deles seria explorar o potencial criativo e inclusivo do brincar com os brinquedos não estruturados. Há potencial inclusivo no brincar com os brinquedos não estruturados, quando este ato criativo se sustenta nos princípios éticos e estéticos multiculturais. Cabe à professoras e professores oportunizarem a livre expressão de meninas e meninos no ato de brincar.

\section{O POTENCIAL INCLUSIVO DO BRINCAR NA EDUCAÇÃO INFANTIL}

$\mathrm{O}$ ato de brincar nos remete às culturas infantis quando reconhecemos que as crianças, desde pequenas, sabem muitas coisas e têm, na brincadeira, uma importante ferramenta de expressão, aprendizagem, desenvolvimento e, consequentemente, de circulação e preservação lúdica. Entendemos que o ato de brincar não é inato, ele é construído, aprendido no movimento próprio das culturas infantis. Na Educação Infantil ele deve ser o principal meio de construção de conhecimentos e apropriação cultural. Portanto, as instituições de Educação

\begin{tabular}{l|c|c|c|c|c|c} 
() Rev. Educ. Perspec. & Viçosa, $M G$ & v.9 & n.2 & p.414-433 & maio/ago. 2018 & eISSN 2178-8359 \\
\hline
\end{tabular}


Infantil devem garantir processos de criação e de compreensão das manifestações infantis na integração do ato de brincar no cuidar/educar.

Como ato de construção, se aproximado aos princípios da educação inclusiva (criança como sujeito de direito, respeito às diferenças, diversidade e igualdade de acesso), o brincar adquire potencial inclusivo. Neste sentido, especialmente, serão as múltiplas linguagens que oportunizarão a ampliação da expressão dos livres movimentos, do acolhimento, do cuidado e do respeito num contínuo processo do "aprender e ensinar brincando" nas instituições de Educação Infantil.

A brincadeira deve estar integrada às diferentes expressões (GOBBI, 2010), como elemento cultural de continuidade do lar na creche e pré-escola, mas também como espaço de criação e reinvenção, por exemplo, na ressignificação de um brinquedo. Neste sentido, Gobbi (2010) destaca alguns dos desafios da Educação Infantil no Brasil, tais como: garantir processos de criação e de manifestações infantis em sua inteireza, considerar as linguagens associadas ao movimento, ao desenho e à dramatização. Entendemos que a perspectiva da reinvenção é um importante elemento se pretendemos superar as marcações de raça e gênero que produzem segregação, hierarquização e exclusão também nas instituições de Educação Infantil.

As instituições educacionais devem oportunizar tanto o conhecer brincadeiras antigas (partilhando os repertórios das diferentes crianças) como o inventar novas formas de brincar (garantindo processos de criação) por meio de diferentes linguagens artísticas, dramáticas, plásticas, musicais, verbais, gestuais, etc. Neste processo pode se dar também a reinvenção, a qual tem potencial para neutralizar, por exemplo, as fronteiras dicotômicas (meninas/meninos e brancos/negros) tradicionalmente postas em algumas brincadeiras. Ao invés de hierarquizar, é possível misturar, integrando as diferenças neste movimento criativo do brincar.

Nesta perspectiva, há que esclarecermos que o brinquedo é o objeto de suporte da brincadeira (KISHIMOTO, 1993) e pode ser apresentado também como não estruturado. Os brinquedos não estruturados nos remetem a objetos que se tornam brinquedos no ato de invenção e criação da criança. Ou seja, ele é um objeto de suporte que não define a brincadeira previamente. Com os brinquedos não estruturados, as crianças são capazes de ressignificar e transformar objetos do cotidiano, vivenciando ricas oportunidades de aprendizagem e ressignificação dos artefatos culturais.

Pensando na valorização da diversidade das culturas infantis, a seguir, apresentaremos algumas experiências que destacam a importância de se trabalhar as múltiplas linguagens na Educação Infantil. A diversidade pode qualificar brincadeiras e brinquedos não estruturados, por isso propomos um trabalho educativo interdisciplinar que permita, às crianças, serem

\begin{tabular}{l|l|l|l|l|l|l} 
(C) Rev. Educ. Perspec. & Viçosa, $M G$ & v.9 & n.2 & p.414-433 & maio/ago. 2018 & eISSN 2178-8359 \\
\hline
\end{tabular}


protagonistas de sua própria aprendizagem, rompendo com a marcação da diferença para a exclusão.

Se o padrão se reflete nos tipos de brinquedos e materiais estruturados que são disponibilizados às crianças na Educação Infantil, importa refletirmos como os brinquedos oferecidos às crianças estão carregados de expectativas, simbologias e intenções. Há que organizarmos e reorganizarmos os espaços destinados às crianças com propostas educativas inclusivas voltadas para jogos de cooperação, brinquedos não estruturados e brincadeiras com o objetivo de descaracterizar os padrões que reproduzem os valores estéticos racistas e de marcação e hierarquização de gênero entre meninos e meninas.

\begin{abstract}
As brincadeiras de transformação do corpo eram importantes momentos para meninos e meninas: brincar de rodar com a saia, brincar de maquiar o rosto e colorir os lábios com batom, brincar de ter cabelos compridos, usar colar, chapéu, óculos e brinco... As brincadeiras que enfeitam o corpo, brincadeiras que transformam o corpo encantam as crianças, meninas e meninos (FINCO; OLIVEIRA, 2011, p. 73).
\end{abstract}

Trabalhar a diferença de forma inclusiva exige a reorganização dos ambientes e brincadeiras, colocando à disposição das crianças diferentes artefatos culturais, expressões musicais e livros que promovam a aprendizagem para a igualdade racial e igualdade de gênero. Brincadeiras que promovam a construção da autoestima positiva serão fundamentais. Diversificar o brincar é transformador. Brincar com fotos ou imagens que representem positivamente a diversidade racial brasileira. Brincar de casinha, compartilhando tarefas entre meninas e meninos, onde ambos aprendem a cuidar juntos. Inserir bonecas e bonecos que representem a pluralidade fenotípica (diferentes tons de pele, textura de cabelo, etc) que caracteriza a população brasileira. Brincar com livros que sejam portadores de texto que valorize a igualdade de gênero e igualdade racial. Enfim, são múltiplas as possibilidades e é possível superar a monocultura nos espaços educacionais.

A finalidade dessas ações, atividades, brincadeiras e brinquedos que propomos é que "crianças aprendam desde muito cedo a tomar decisões, a assumir responsabilidades e a não deixar que sua própria voz seja silenciada pelos que falam mais alto ou projetam formas de exclusão" (HERNANDEZ, 2001, p. 592) por meio da marcação de gênero e de raça. Estas dimensões exigem o olhar sensível de professoras e professores para a eliminação de barreiras físicas, comunicacionais ou atitudinais também no ato de brincar.

A criatividade, a criticidade e o protagonismo fazem parte também do mundo das crianças pequenas. O desafio está presente na rotina de toda sala de aula, independente da modalidade, instituição, estado ou rede de ensino. Com os brinquedos não estruturados, a intenção é não marcar os corpos das crianças com "isso é de menino" ou "isso só serve para meninas". Os brinquedos não estruturados, por exemplo, podem oportunizar o conhecimento e valorização

\begin{tabular}{l|l|l|l|l|l|l} 
(C) Rev. Educ. Perspec. & Viçosa, $M G$ & v.9 & n.2 & p.414-433 & maio/ago. 2018 & eISSN 2178-8359 \\
\hline
\end{tabular}


da estética e cultura do povo negro por meio do uso dos diferentes artefatos culturais na instituição educacional.

Acreditamos que o brinquedo estruturado pode acabar legitimando as diferenças de forma discriminatória entre as crianças, uma vez que lhes são impostos os padrões da estética, da feminilidade e da masculinidade como os modelos impostos pela sociedade. O brinquedo estruturado pode ditar regras para que os meninos e as meninas se comportem e ajam de acordo com o sentido social atribuído ao seu sexo, à cor da sua pele e à textura do seu cabelo.

Ao brincar, as crianças exploram suas características e possibilidades, testam hipóteses, atribuem novas funções e, sobretudo, experienciam o prazer de criar e recriar a própria brincadeira. Entendemos que o oferecimento de objetos não estruturados oportuniza a resolução criativa de problemas, pois as crianças ficam muito mais tempo envolvidas na brincadeira. Elas têm que construir o que, diferentemente do brinquedo estruturado/comercializado, não veio pronto.

Há múltiplas possibilidades para o brincar, por exemplo, nos "cantos pedagógicos" que são espaços educativos com os quais a criança interage e estabelece relações. Nos cotidianos da Educação Infantil, esta vivência tem sido extremamente significativa, pela descoberta, envolvimento e interação das crianças com os materiais não estruturados dispostos nestes diferentes cantos. Brincando a criança vai compreendendo e ressignificando o mundo, experimentando novas formas de ser e pensar, o que afirma a criança como sujeito histórico e produtor de cultura. Todavia, há sempre que considerarmos a intencionalidade na organização dos espaços, materiais e tempos para a promoção da igualdade racial no campo da Educação Infantil.

Os profissionais que atuam na Educação Infantil devem considerar que, por vezes, os "objetos traduzem determinadas ideologias e concepções que educam em uma direção que esses profissionais não planejam e que não o fariam intencionalmente" (BRASIL, 2012, p. 19-20). É preciso diagnosticar como e quais crianças estão representadas nos murais da instituição de Educação Infantil e agir. É preciso pesquisar, em equipe, as "imagens que podem compor um acervo para a igualdade racial: reproduções de imagens de arte africana, de negros em situações de protagonismo, etc" (BRASIL, 2012, p. 20). Mas também é preciso aplicar este conhecimento nos cotidianos da instituição educacional, a começar pelos cantos pedagógicos.

A literatura também favorece a construção de um olhar diferenciado para as relações raciais, pois o livro pode ser portador de texto que valorize a igualdade racial. Tendo em vista este princípio, destacamos o livro "Nino e Bela", de Regina Rennó. A narrativa deste livro, ao

\begin{tabular}{l|l|l|l|l|l|l} 
(C) Rev. Educ. Perspec. & Viçosa, $M G$ & v.9 & n.2 & p.414-433 & maio/ago. 2018 & eISSN 2178-8359 \\
\hline
\end{tabular}


projetar, positivamente, um personagem negro e um "não negro", sob um olhar das relações étnico-raciais, discorre sobre a ação de duas crianças que brincam. Num primeiro momento, a professora conta a história procurando envolver as crianças no enredo. Após esta contação, a professora realiza uma roda para que as crianças verbalizem suas emoções no campo das questões étnico-raciais. $\mathrm{O}$ ato de narrar novamente a história permite que as crianças criem conceitos, ideias, construindo, explorando e reinventando os saberes cotidianos sobre a convivência entre crianças negras e brancas a partir das diferentes realidades em que vivem.

Enfim, tal qual Kishimoto (1993), entendemos que a infância é também a idade do possível. Pode-se projetar sobre ela a esperança de mudança, de transformação social e renovação moral. Brincando e fantasiando, a criança pode reviver angústias, conflitos, alegrias, desistir e refazer, deixando de lado a sujeição às ordens e exigências dos adultos, numa sociedade que as pressiona para assimilar valores, crenças, leis, regras, hábitos, costumes, princípios e linguagens. As crianças são capazes, portanto, de lidar com as complexas realidades sociais através do ato de brincar e de construir seus próprios brinquedos.

\section{CONSIDERAÇÕES FINAIS}

O estatuto e os papéis sociais são atribuídos à infância historicamente e mudam conforme variações sociais (classe social, etnia, religião, gênero, idade, etc.). Neste sentido, há que celebrarmos a centralidade da criança como sujeito de direito nas políticas públicas atuais. Todavia, estas grandes conquistas situam-se em quadros sociais complexos e exigem enfrentamentos na transição paradigmática contemporânea. Há impasses importantes nesta tessitura que carecem de discussão e de proposta de novas práticas. Entendemos que as questões da etnia e gênero são dois destes nós que precisamos desatar no campo da Educação Infantil.

No decorrer dos estudos sobre a Educação Inclusiva, nós, professoras, num processo reflexivo sobre a própria prática, construímos duas proposições e, aqui, as compartilhamos. Primeiro, entendemos que há meios para romper com a marcação de raça e gênero nos cotidianos das instituições de Educação Infantil. Segundo, reconhecemos o potencial inclusivo nas brincadeiras e no brincar com os brinquedos não estruturados, quando estes sustentam-se nos princípios éticos e estéticos multiculturais.

$\mathrm{Na}$ busca pelo reconhecimento e respeito das diferentes formas de sensoriamento do mundo pelas diferentes crianças, as instituições de Educação Infantil, com base nos princípios éticos e estéticos que as sustentam, precisam das múltiplas linguagens para a construção do espaço educacional inclusivo. Todavia, há que investirmos na formação estética e ética dos

\begin{tabular}{l|c|c|c|c|c|c} 
() Rev. Educ. Perspec. & Viçosa, $M G$ & v.9 & n.2 & p.414-433 & maio/ago. 2018 & eISSN 2178-8359 \\
\hline
\end{tabular}


professores e professoras, no sentido da constituição de novos processos de criação e compreensão das manifestações infantis nas instituições de Educação Infantil.

Importa, portanto, considerarmos as intencionalidades didáticas que permeiem a integração do cuidar/educar no sentido da garantia dos direitos educacionais de todas as crianças brasileiras, valorizando o brincar como prática da liberdade, da criação, do respeito e da valorização das diferenças (sem hierarquizá-las) no campo da Educação Infantil brasileira.

\section{REFERÊNCIAS}

BRASIL. Constituição da República Federativa do Brasil. Brasília, 1988.

BRASIL. Lei N. 11.645, de março de 2008. Estabelece as diretrizes e bases da educação nacional, para incluir no currículo oficial da Rede de Ensino a obrigatoriedade da temática "História e Cultura Afro-Brasileira e Indígena". Brasília, 2008.

BRASIL. Ministério da Educação. Lei N. 9.394, de 20 de dezembro de 1996. Estabelece as diretrizes e bases da educação nacional. Brasília, 1996.

BRASIL. Conselho Nacional de Educação. Resolução N. 1, de 17 de junho de 2004. Institui as diretrizes curriculares nacionais para a educação das relações étnico-raciais e para o ensino de História e Cultura Afro-brasileira e Africana. Disponível em:

http://portal.mec.gov.br/cne/arquivos/pdf/res012004.pdf. Acesso em: 29 abr. 2018.

\section{BRASIL. Ministério da Educação. Diretrizes Curriculares Nacionais para a Educação} Infantil. Brasília, 2010.

BRASIL. Ministério da Educação. Educação infantil e práticas promotoras de igualdade racial. São Paulo: CEERT/Instituto Avisa lá, 2012. Disponível em:

http://www.avisala.org.br/wp-content/uploads/2015/06/revistadeeducacaoinfantil_2012.pdf. Acesso em: 29 abr. 2018.

FINCO, Daniela; OLIVEIRA, Fabiana de. A sociologia da pequena infância e a diversidade de gênero e de raça nas instituições de educação infantil. In: FARIA, Ana Lúcia Goulart de; FINCO, Daniela (Org.). Sociologia da infância no Brasil. São Paulo: Autores Associados, 2011. p. 55-80.

FREIRE, Paulo. Pedagogia da autonomia: saberes necessários a prática educativa: Rio de Janeiro: Paz e Terra, 1997. 320p.

GOBBI, Márcia. Múltiplas linguagens de meninos e meninas no cotidiano da Educação Infantil. Disponível em:

\begin{tabular}{l|c|c|c|c|c|c} 
(C) Rev. Educ. Perspec. & Viçosa, $M G$ & v.9 & n.2 & p.414-433 & maio/ago. 2018 & eISSN 2178-8359 \\
\hline
\end{tabular}


http://portal.mec.gov.br/index.php?option=com_docman\&view=download\&alias $=6678$ multiplaslinguagens\&category_slug=setembro-2010-pdf\&Itemid=30192. Acesso em: 29 abr. 2018.

GOFFMAN, Erving. Estigma: notas sobre a manipulação da identidade deteriorada. Rio de Janeiro: Guanabara Koogan, 1988. 158p.

GOMES, Nilma Lino. Sem perder a raiz: corpo e cabelo como símbolos da identidade negra. Belo Horizonte: Autêntica, 2007. 471p

HERNANDEZ, Fernando. Os projetos de trabalho. Revista de Educação. Porto Alegre, v. 3, n. 4, p. 2-7, 2001.

KISHIMOTO, Tizuco Morchida (Org.) Jogo, brinquedo, brincadeira e a educação. 3 ed. São Paulo: Cortez 1993. 207p.

KUHLMANN, Moysés Jr. Histórias da Educação Infantil Brasileira. Revista Brasileira de Educação. Rev. Bras. Educ. [online]. Rio de Janeiro, n. 14, p. 5-18, maio/ago. 2000.

MANTOAN, Maria Teresa Eglér. Para uma escola do século XXI. Campinas: UNICAMP, 2013. 122p.

MOSS, Peter. Introduzindo a política na creche: a Educação Infantil como prática democrática. Revista Psicologia USP. São Paulo, v. 20, n. 3, p. 417- 436, jul./set. 2009.

MOURA, Tainá Narô da Silva de. Gênero e relações étnico-raciais no mercado de trabalho: aparência da mulher negra na organização. 2013. 64 f. Monografia (Bacharelado em Comunicação Organizacional). Universidade de Brasília, Brasília, 2013.

NOVA, Daniel. Pantera Negra e a importância da representatividade. 2017. Disponível em: https://medium.com/@ danielvnova/pantera-negra-e-a-import\%C3\%A2ncia-darepresentatividade-6d95cd7a7a4a. Acesso em: 4 fev. 2018.

OLIVEIRA, Zilma de Morais Ramos de. A criança e seu desenvolvimento: perspectivas para se discutir a educação infantil. 4 ed. São Paulo: Cortez, 2000. 159p.

ONU. Relatório sobre as minorias no Brasil. 2016. Disponível em:

https://nacoesunidas.org/brasil-violencia-pobreza-e-criminalizacao-ainda-tem-cor-dizrelatora-da-onu-sobre-minorias/. Acesso em: 4 fev. 2018.

PIBID, Filosofia/UFMT. Filosofia e consciência negra. 2010. Disponível em: http://media.wix.com/ugd/8c4916_3f4c248607644424927be4f92f9fb130.pdf. Acesso em: 9 mar. 2018. 
SANTOS, Boaventura de Sousa. A gramática do tempo: para uma nova cultura política. São Paulo: Cortez, 2008. 512p.

\section{SOBRE AS AUTORAS}

${ }^{1}$ Elizabete Cristina Costa-Renders - Pós Doutora e Doutora em Educação pela Universidade Estadual de Campinas. Docente da Universidade Municipal de São Caetano do Sul. E-mail: elizabetecostarenders@gmail.com - ORCID: https://orcid.org/0000-0002-1219-9382

${ }^{2}$ Rosana Donizeti Martinho Gazotto - Mestranda em Educação pela Universidade Municipal de São Caetano do Sul. E-mail: rosana gazotto@ hotmail.com - ORCID: https://orcid.org/0000-0003-2140$\underline{8745}$

${ }^{3}$ Cleia Souza Santos - Mestranda em Educação pela Universidade Municipal de São Caetano do Sul. E-mail: cleiatulipa53@ gmail.com - ORCID: http://orcid.org/0000-0001-7397-7590 